American Journal of Applied Sciences 9 (5): 694-699, 2012

ISSN 1546-9239

(C) 2012 Science Publications

\title{
Dielectric Properties of Collagen on Plasma Modified Polyvinylidene Fluoride
}

\author{
Dahan, R.M., S.I. Ismail, Famiza Latif, \\ M.N. Sarip, M.H. Wahid and A.N. Arshad \\ Department of Polymer, Faculty of Applied Sciences, \\ University Technology MARA, 40450 Shah Alam, Malaysia
}

\begin{abstract}
Problem statement: The attachment of biopolymers such as collagen on inert polymeric template created great challenge due to hydrophobic nature of polymeric material. The modification of PVDF for improved adhesion and introduction of specific functionalities have been widely recognized in various industrial applications. Typical methods for modifying polymer surface such as chemical etching and UV irradiation are not favorable as it requires high temperature and the use of chemical solvents. However plasma modification is suitable as it utilizes low heat and a clean environment, thus preventing contamination on the deposited collagen. Approach: Free standing orientated Poly (Vinylidene Fluoride) (PVDF) films were fabricated by solution casting method and dried in a convention oven. The dried PVDF films were orientated in a tensile machine at temperature $70^{\circ} \mathrm{C}$ enclosed in a custom made environmental chamber. The pulling rates of $5 \mathrm{~mm} \mathrm{~min}^{-1}$ were utilized with a draw ratio of 2 ( $\mathrm{R}=$ $\left.\mathrm{L}_{\text {final }} / \mathrm{L}_{\text {initial }}\right)$. The PVDF film was plasma treated for $60 \mathrm{sec}$ to enhance the hydrophilic property of PVDF and utilized as template for collagen deposition. The deposited collagen on surface of PVDF was left in desiccators at temperature of $24^{\circ} \mathrm{C}$ for complete drying. Results: The untreated and plasma-treated PVDF template were observed for water contact angle measurement, the functional group and dielectric properties of collagen were observed and measured by FTIR and SOLARTRON respectively. Conclusion: The orientated PVDF films were produced at pulling speed of $5 \mathrm{~mm} \mathrm{~min} \mathrm{~m}^{-1}$ and temperature of $70^{\circ} \mathrm{C}$. The hydrophobic PVDF surface was transformed to a hydrophilic surface by plasma treatment for collagen deposition. The FTIR result shows the overlapping peaks of C-H and C-F in range 1500$1000 \mathrm{~cm}^{-1}$ which indicates the C-C bonding of collagen and PVDF. The significant increase in dielectric constant is a result from the favorable bonding between collagen and PVDF template.
\end{abstract}

Key words: Orientation, hydrophobic, collagen, PVDF, dielectric constant

\section{INTRODUCTION}

Collagen have been used widely used for medical application especially in the field of tissue engineering, which include areas such as regeneration of new tissues and new organs, artificial prosthetic in joints, connective tissues or blood vessels. These collagen are able to create a three dimensional living cells and promote cell growth by generating molecular signals at the specific areas which will induce a tissue repair responses (Griffith, 2000; Nasir et al., 2006). They are usually extracted from tissues of skin or bones and consit of highly oriented crystalline fibers, however the molecules lose their ordered conformation and appeared as random structures. Some studies instigated the self assembly of collagen films by variation of $\mathrm{pH}$ and electrolyte of the buffer solutions (Jiang et al., 2004).
Many studies have been carried out to investigate structures and surface morphology of collagen adsorbed on various polymer (Dufrene et al., 1999a; 1999b; Dupont-Gillain et al., 1999). Polymer surfaces, covered with organic molecules have attracted much attention in the development of sensors, molecular electronic devices as well as in the assembly of supramolecular structures (Lowe, 2000). Collagen is utilized for coating PVDF substrates. Collagen exhibits biodegradability, has excellent biocompatibility, as well as safe to use in medical field due to its biological characteristics (Maeda, 1999).

PVDF being an inert and stable material is a suitable supporting substrate for biopolymer depositions.

PVDF are materials of large technological importance and they are characterized by high chemical inertness, thermal stability and electrical insulating properties. They also have very low surface tension, which causes

Corresponding Author: Dahan, R.M., Department of Polymer, Faculty of Applied Sciences, University Technology MARA, 40450 Shah Alam, Malaysia 
negligible adhesion to other materials, especially metals (Duca et al., 1998). PVDF has created interest in numerous researchers, due to the dielectric properties which constitute from its net polarization. Net polarization generates dielectric properties for that particular sample and this property had been applied worldwide and mainly used as capacitors in electronic devices. The study of stretched PVDFf films and PVDF composite show high $\beta$ phases in comparison to unstreched PVDF films (Salimi and Yousefi, 2003; Sun et al., 2010).

There is lack of study of the effect of electrical properties of deposited biomaterials on oriented PVDF films. Even though PVDF do not posses surface properties needed for deposition of other materials, PVDF still is the common materials used for capacitors and other electronic devices applications due to their excellent electrical properties, bulk physical and chemical properties and are easy to process. For these reasons, surface modification techniques can be applied to transform these inexpensive materials into valuable finish product and being an important part in many plastics industry (Meng et al., 2011). Nowadays, many researchers have been developing polymer surface treatments to alter the chemical and physical properties of polymer surfaces without affecting bulk properties. The one that is being focused here is plasma treatment due to its clean process. Plasma treatments alter the surface energy of most polymers, changing their surface polarity, wettability and adhesive characteristics. Surface activation takes place during the plasma process mainly by hydrogen abstraction and radical formation, which results in modification of only the top-most nanometers of the polymer structure being altered (Kull et al., 2005). The objective of this study focused on producing deposited collagen on orientated PVDF template and to measure the dielectric constant of collagen using SOLATRON.

\section{MATERIALS AND METHODS}

Template preparation: PVDF (Sigma Aldrich Co. Ltd, United Kingdom) and DMF (Sigma Aldrich Co. Ltd, United Kingdom) were diluted to 10M. 4 grams PVDF and $30 \mathrm{~mL}$ DMF 10M solution were stirred for $2 \mathrm{~h}$ until complete dissolution, casted into glass petri dish and evaporated in an oven at temperature $70^{\circ} \mathrm{C}$ for $12 \mathrm{~h}$. PVDF films of 0.2-0.4 $\mathrm{mm}$ was stretched by tensile machine at stretching rate of $5 \mathrm{~mm} \mathrm{~min}^{-1}$ at temperature $70^{\circ} \mathrm{C}$. The stretched PVDF surface undergoes surface modification by plasma treatment of Argon (Ar) gas for $60 \mathrm{sec}$.

Collagen deposition: Type I Collagen from bovine was dissolved in mild acetic acid with ratio acetic acid: deionized water of 0.1:9.9 ( $\mathrm{vol} / \mathrm{vol}) .4 \mathrm{gm}$ of collagen was dissolved into $200 \mathrm{~mL}$ mild acetic acid, deposited on treated-stretched PVDF template by dipping process for $2 \mathrm{~h}$. Deposited collagen was dried vertically in desiccator of temperature $24^{\circ} \mathrm{C}$.

Experimental setup: The functional group of PVDF and collagen was analyzed by FTIR model Perkin Elmer-7 in which the fingerprint region of PVDF lies in the range of $1500 \mathrm{~cm}^{-1}$ until $600 \mathrm{~cm}^{-1}$. The wave numbers selected for deposited collagen on PVDF template was in range of 4000-600 $\mathrm{cm}^{-1}$ which accounts for C-N-H $\sim 3300 \mathrm{~cm}^{-1}$ and C-H $\sim 1600 \mathrm{~cm}^{-1}$ till $1200 \mathrm{~cm}^{-1}$. Dielectric constant is a response of charges, generated when PVDF and collagen is applied to strong electric field. The dielectric properties of PVDF template and deposited collagen were measured using SOLARTRON SI 1260. The study was carried out at the frequency range from $100 \mathrm{~Hz}$ to $1 \mathrm{MHz}$ at ambient temperature.

\section{RESULTS}

Contact angle measurement: The contact angles are measured for both untreated and plasma treated collagen deposited PVDF films. Figure 1 shows the contact angle of untreated surface PVDF template, prior to plasma treatment. The angles on both sides were $95^{\circ}$, indicating the untreated PVDF template is highly hydrophobic. This suggests that PVDF, being a predominantly fluorine based material caused the repulsion of water droplet.

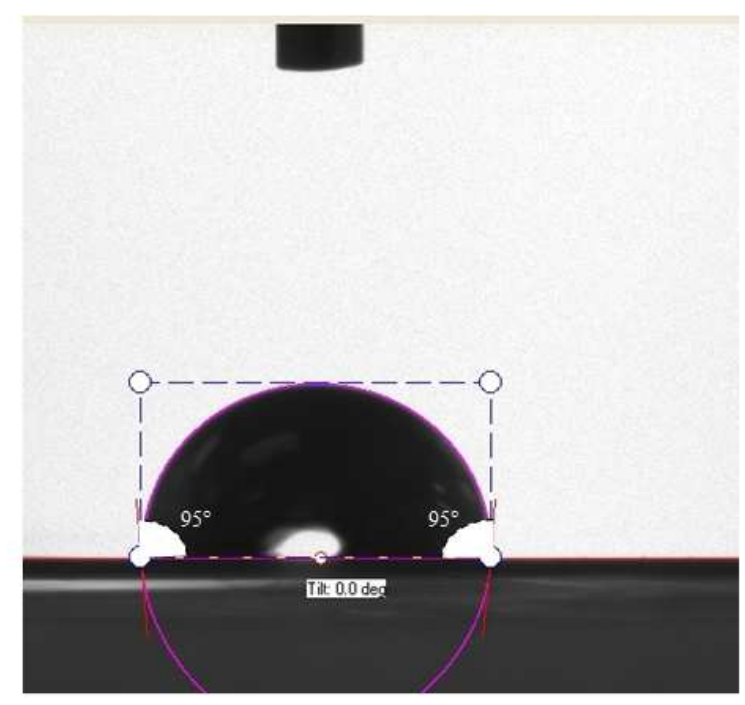

Fig. 1: Contact angles of untreated-stretched surface PVDF template 


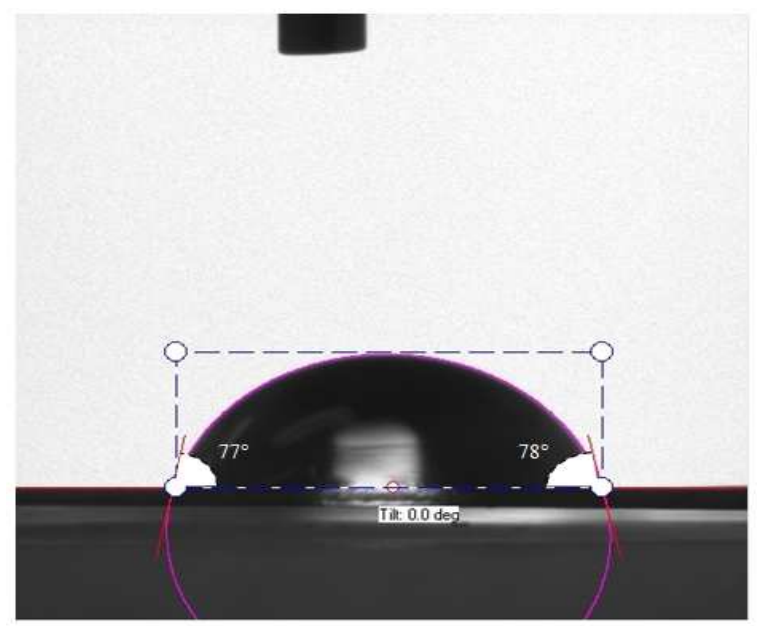

Fig. 2: Contact angles of treated-stretched surface PVDF template

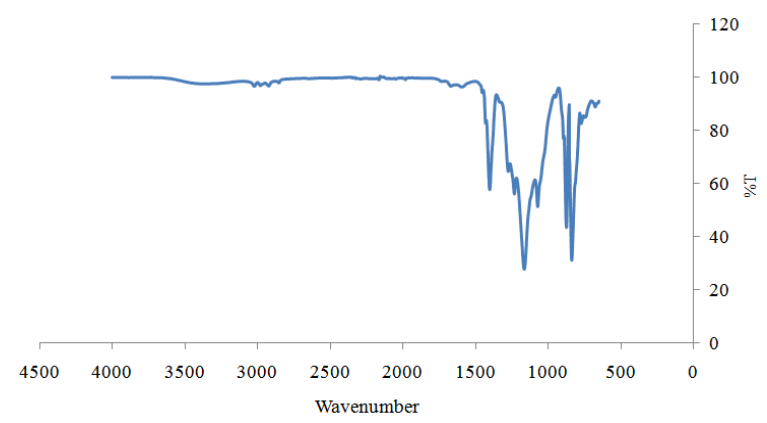

Fig. 3: FTIR spectra of unstretched PVDF

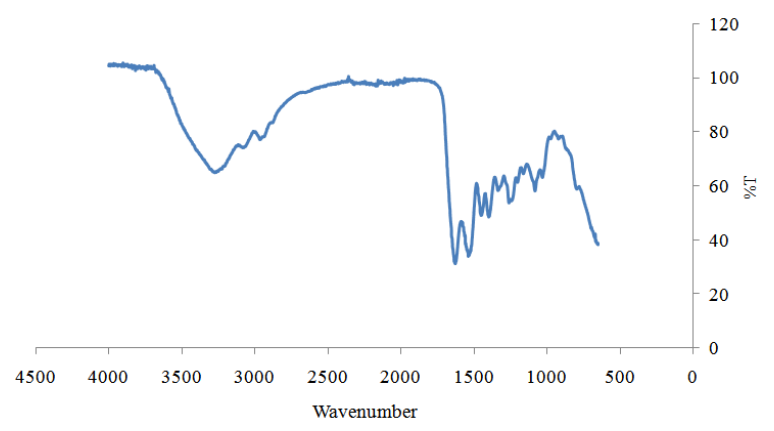

Fig. 4: FTIR spectra of collagen

Figure 2 shows contact angle of post plasma treated $(60 \mathrm{sec})$ surface of PVDF template. The treated surface shows a significant reduction of angle of the water droplet to $78^{\circ}$ (right) and $77^{\circ}$ (left). This result indicates the phenomenon of fluorine scission of the treated template which transformed the hydrophobic PVDF surface to a hydrophilic PVDF surface and enhanced the adhesion water droplet due to the C-C of water droplet with treated PVDF template.

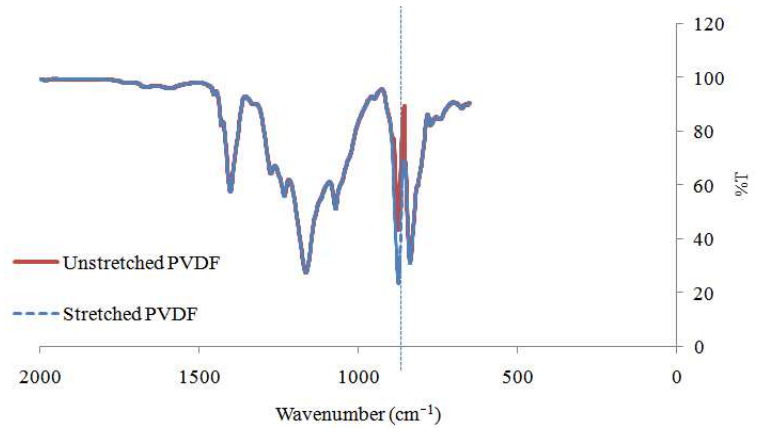

Fig. 5: FTIR spectrum of unstretched PVDF and PVDF stretched at $70^{\circ} \mathrm{C}$

FTIR analysis

Controlled Polyvinylidene Fluoride (PVDF) and collagen: The fingerprint region of PVDF and collagen are measured within range $4000-650 \mathrm{~cm}^{-1}$.

Figure 3 shows the FTIR spectrum of unstretched PVDF. The fingerprint region of PVDF film can be observed at $1230 \mathrm{~cm}^{-1}$ for CF bond and $840 \mathrm{~cm}^{-1}$ for $\mathrm{CF}_{2}$ bond. Range between $1250 \mathrm{~cm}^{-1}$ until $1000 \mathrm{~cm}^{-1}$ relates on the $\mathrm{CH}$ stretching. The vibration band at 763 $\mathrm{cm}^{-1}$ accounts for $\mathrm{CF}_{2}$ bending and skeletal bending of $\alpha$-phase, which is supported by studies where and the $840 \mathrm{~cm}^{-1}$ is attributed to the $\mathrm{CF}_{2}$ asymmetric stretching vibration of $\beta$-phase and $763 \mathrm{~cm}^{-1}$ for $\alpha$-phase (Costa et al., 2009; Salimi and Yousefi, 2003; Sun et al., 2010). The result shows no peak at 1670 and $1500 \mathrm{~cm}^{-1}$, which indicates the absence of $\mathrm{C}=\mathrm{O}$ and $\mathrm{C}-\mathrm{N}$ respectively. Hence it is assumed that most of the DMF have vaporized (Jacob and Arof, 2000). Therefore the film is safe to be used for biological application.

Figure 4 shows the FTIR spectrum of collagen in the range of $3300-3000 \mathrm{~cm}^{-1}$ for primary amine of $\mathrm{N}-\mathrm{H}$, $1650 \mathrm{~cm}^{-1}$; for $\mathrm{C}=\mathrm{O}, \mathrm{N}-\mathrm{H}_{2}$ and $\mathrm{N}-\mathrm{H}$ wagging, 1551 $\mathrm{cm}^{-1}$ for $\mathrm{N}-\mathrm{H}_{2}$ scissoring of the secondary ammines and $1250-1000 \mathrm{~cm}^{-1}$ for $\mathrm{C}-\mathrm{N}$. This is consistent to observation made by (Bryan et al., 2007).

Unstretched and stretched PVDF: Figure 5 shows FTIR spectrum of untreated-stretched PVDF $\left(70^{\circ} \mathrm{C}\right)$ with respect to the unstretched PVDF. Significant decreased in intensity was observed at the wave number $840 \mathrm{~cm}^{-1}$ of the unstretched PVDF (45\% T) incomparison to the streched PVDF (25\%T). This suggests the PVDF phase transformation from $\alpha$ phase to $\beta$-phase, which is supported by respective studies (Lanceros-Mendez et al., 2001) and (Mano et al., 2004). 
Am. J. Applied Sci., 9 (5): 694-699, 2012

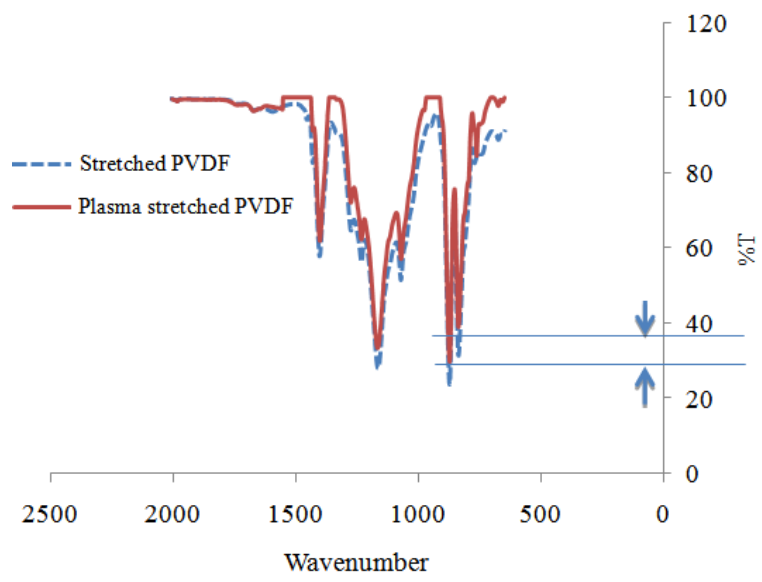

Fig. 6: FTIR spectrum of stretched PVDF and plasma Treated-Stretched PVDF

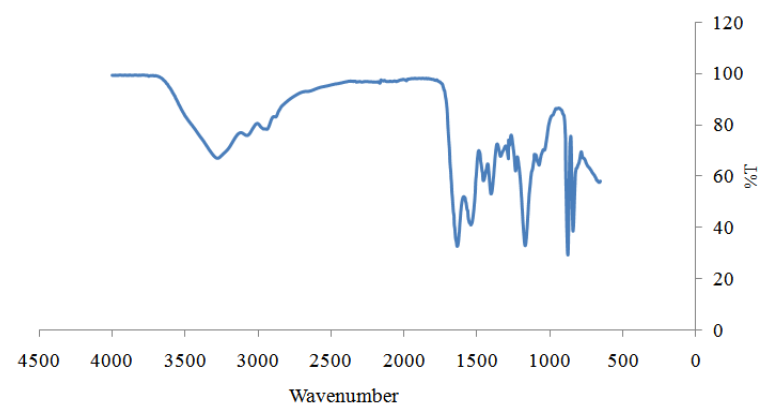

Fig. 7: FTIR spectra of collagen deposited on treatedstretched PVDF template

Treated-stretched PVDF: Figure 6 shows the FTIR spectrum of stretched PVDF (dotted lines), while plasma treated-stretched PVDF is shown by the smooth line. A significant increase in intensity was observed throughout the fingerprint region of the treatedstretched PVDF. The arrow indicates a $10 \% \mathrm{~T}$ increase in intensity of the treated-stretched PVDF.

Collagen on treated-stretched PVDF: Figure 7 shows FTIR spectrum of collagen deposited on treatedstretched PVDF template. The spectrum shows peaks of 1230,840 and $763 \mathrm{~cm}^{-1}$ which indicates the presence of $\mathrm{C}-\mathrm{F}$, which is consistent to the fingenprint spectra from literature (Duca et al., 1998). Unique collagen band peak at $3300-3000 \mathrm{~cm}^{-1}$ for primary amine, $\mathrm{C}=\mathrm{O}$ at $1650 \mathrm{~cm}^{-1}, \mathrm{NH}_{2}$ and $\mathrm{NH}$ at $1550 \mathrm{~cm}^{-1}$ were observed. Peaks in region 1400-1000 cm compatibilty between PVDF surface and collagen film, due to the active $\mathrm{C}-\mathrm{C}$ radicals which react with the amine group in polypeptide chain. This also proved that plasma treatment can assist PVDF template in terms of hydropbobic to a hydrophilic surface.

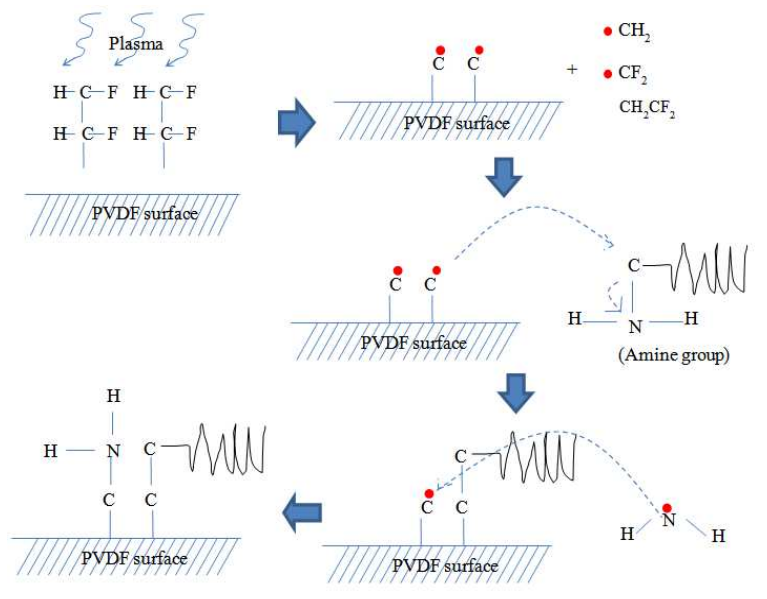

Fig. 8: C-C mechanism of treated-stretched PVDF with collagen

Figure 8 shows $\mathrm{C}-\mathrm{H}$ and $\mathrm{C}-\mathrm{F}$ scission mechanism between collagen deposited on treated-stretched PVDF. During post plasma treatment, highly active carbon radicals were formed on the PVDF surface by the scission of $\mathrm{C}-\mathrm{H}$ and $\mathrm{C}-\mathrm{F}$ groups. The tendency for radical attack produced from these radicals to collagen with long branched amine group is favorable. These highly active carbon radical of PVDF attacked other neighboring amine group, leaving $\mathrm{NH}_{2}$ radical. This produced a chain reaction in which the $\mathrm{NH}_{2}$ radical will subsequently react with the neighboring molecule. The process will continue until the formation of a stable $\mathrm{NH}_{2}$ upon reacting with another carbon radical of the PVDF.

Dielectric measurements: The dielectric calculation was carried out using Eq. 1 (Majid and Arof, 2007; Dupont-Gillain et al., 1999):

$$
E=\frac{-\omega C_{0} Z_{i}}{\left(\omega C_{\mathrm{o}}\right)^{2}\left[\left(\mathrm{Zr}^{2}+\mathrm{Zi}^{2}\right)\right]}+\frac{\omega \mathrm{C}_{\mathrm{o}} \mathrm{Z}_{\mathrm{r}}}{\left(\omega \mathrm{C}_{\mathrm{o}}\right)^{2}\left[\left(\mathrm{Zr}^{2}+\mathrm{Zi}^{2}\right)\right]}
$$

Where:

$$
\begin{aligned}
\mathrm{E} & =\text { Dielectric constant } \\
\Omega & =2 \pi \mathrm{f} \\
\mathrm{f} & =\text { Frequency } \\
\mathrm{C}_{\mathrm{o}} & =\left(\varepsilon_{\mathrm{o}} \mathrm{X} \text { Area }\right) / \text { Thickness } \\
\mathrm{Zi}, \mathrm{Zr}= & \text { Imaginary and real value of impedance } \\
& \text { conductivity }
\end{aligned}
$$

Table 1 shows the dielectric constant, $\mathrm{E}$ for unstretched PVDF, treated-unstretched PVDF and collagen deposited on treated-unstretched PVDF. The E for unstretched PVDF is found to be 3.95 . 
Am. J. Applied Sci., 9 (5): 694-699, 2012

Table 1: Magnitude of dielectric constant, $\mathrm{E}_{100 \mathrm{~Hz}}$ for unstretched PVDF, treated-unstretched PVDF and treated-unstretched PVDF with collagen

\begin{tabular}{ll}
\hline Parameters & $\mathrm{E}_{100 \mathrm{~Hz}}$ \\
\hline Unstretched PVDF & 3.95 \\
Treated-Unstretched PVDF & 2.30 \\
Treated-Unstretched PVDF with collagen & 3.92 \\
\hline
\end{tabular}

Table 2: Magnitude of dielectric constant, $\mathrm{E}_{100 \mathrm{~Hz}}$ for stretched PVDF, treated-stretched PVDF and treated-stretched PVDF with collagen

\begin{tabular}{ll}
\hline & $\mathrm{E}_{100 \mathrm{~Hz}}\left(5 \mathrm{~mm} \mathrm{~min}^{-1}\right.$ \\
Parameters & at 70 $\left.{ }^{\circ} \mathrm{C}\right)$ \\
\hline Stretched PVDF & 4.91 \\
Treated-Stretched PVDF & 4.12 \\
Treated-Stretched PVDF with collagen & 4.82 \\
\hline
\end{tabular}

Upon treatment with plasma, the $\mathrm{E}$ of this unstretched PVDF decreases by $40 \%$ in comparison to the untreated PVDF film. Subsequently, when the collagen was deposited on the treated-unstretched PVDF, the magnitude on $\mathrm{E}$ was found to increase significantly.

Table 2 shows the dielectric constant, $\mathrm{E}$ for stretched PVDF $\left(5 \mathrm{~mm} \mathrm{~min}^{-1}\right.$ of $\left.70^{\circ} \mathrm{C}\right)$, treatedstretched PVDF and collagen deposited on treatedstretched PVDF. The modification of the PVDF template by plasma treatment caused the reduction of the fluorine content in the PVDF, which resulted in the decrement of $\mathrm{E}$ from 4.91-4.12. This produced hydrophilic characteristics of the film which enables the adhesion of collagen on the orientated PVDF template, where the E of deposited collagen on PVDF treatedstretched was found to increase to 4.82 .

\section{DISCUSSION}

The surface modification due to plasma treatment the hydrophobic PVDF surface to a hydrophilic PVDF surface and enhanced the adhesion water droplet due to the C-C of water droplet with treated PVDF template (Fig. 1 and 2). PVDF contains abundance of fluorine atom, which repulses any material near its surface. Hoever, upon plasma surface modification, the water contact angle measurement decrease from 95-78 ${ }^{\circ}$ This result indicates chain scission of fluorine atom on the surface of the treated PVDF that caused the surface to become hydrophilic and thus enhanced adhesion of collagen on its surface.

FTIR result shows a significant decrease in intensity from $45-25 \% \mathrm{~T}$ at wave number of $840 \mathrm{~cm}^{-1}$ of the unstretched PVDF incomparison to the streched PVDF. This suggests the PVDF phase transformation from $\alpha$-phase to $\beta$-phase, which is supported by respective studies (Lanceros-Mendez et al., 2001; Mano et al., 2004). The appearance of peaks in region 1400$1000 \mathrm{~cm}^{-1}$ suggest favourable compatibilty between
PVDF surface and collagen film, which may due to the interaction of free radicals that created during plasma modification to $\mathrm{C}-\mathrm{C}$ backbonds with amine group on the chemical structure of collagen. The interaction of free radical on PVDF backbone chain with amine group may lead to the propagation process which is continuously repeated until two of active amine group meet and terminate each other free radical and resulting on stable polymer surface and yield good adhesion between PVDF surface and collagen.

\section{CONCLUSION}

Orientated PVDF films were produced at pulling speed of $5 \mathrm{~mm} \mathrm{~min}^{-1}$ of $70^{\circ} \mathrm{C}$. The orientated hydrophobic PVDF surface transformed to a hydrophilic surface by plasma treatment for collagen deposition. Plasma treated PVDF template shows slight increase in intensity corresponding to the $\mathrm{C}-\mathrm{H}$ and $\mathrm{C}-\mathrm{F}$ scission. Overlapping peaks of $\mathrm{C}-\mathrm{H}$ and $\mathrm{C}-\mathrm{F}$ in range $1500-1000 \mathrm{~cm}^{-1}$ suggests $\mathrm{C}-\mathrm{C}$ bonding of collagen and PVDF. Dielectric constant, E shows deposited collagen on treated PVDF template increased significantly, suggesting a tendency of collagen to follow orientation of PVDF template upon deposition.

\section{ACKNOWLEDGEMENT}

Thanks to University Post Graduate Research Scholarship Grant Scheme from Ministry of Science, Technology and Innovation, Malaysia RMI for supporting this project funds and Universiti Tecknologi MARA for the facilities.

\section{REFERENCES}

Bryan, M.A., J.W. Brauner, G. Anderle, C.R Flach and B. Brodsky et al., 2007. FTIR studies of collagen model peptides: Complementary experimental and simulation approaches to conformation and unfolding. J Am. Chem. Soc., 129: 7877-7884. DOI: $10.1021 / \mathrm{ja} 071154 \mathrm{i}$

Costa, P., J. Silva, V. Sencadas, C.M. Costa and F.W.J.V. Hattum et al., 2009. The effect of fibre concentration on the $\alpha$ to $\beta$-phase transformation, degree of crystallinity and electrical properties of vapour grown carbon nanofibre/poly(vinylidene fluoride) composites. Carbon, 47: 2590-2599. DOI: 10.1016/j.carbon.2009.05.011

Duca, M.D., C.L. Plosceanu and T. Pop, 1998. Surface modifications of Polyvinylidene Fluoride (PVDF) under RF Ar plasma. Polymer Degradation Stability, 61: 65-72. DOI: 10.1016/S01413910(97)00130-4 
Dufrene, Y.F., T.G. Marchal and P.G. Rouxhet, 1999a. Influence of substratum surface properties on the organization of adsorbed collagen Films: In situ characterization by atomic force microscopy. Langmuir, $\quad 15$ : 2871-2878. DOI: 10.1021/la981066z

Dufrene, Y.F., T.G. Marchal and P.G. Rouxhet, 1999b. Probing the organization of adsorbed protein layers: complementarity of atomic force microscopy, X-ray photoelectron spectroscopy and radiolabeling. Applied Surface Sci., 144-145: 638643. DOI: 10.1016/S0169-4332(98)00881-2

Dupont-Gillain, C.C., B. Nysten and P.G. Rouxhet, 1999. Collagen adsorption on poly(methyl methacrylate): Net-like structure formation upon drying. Polymer Int., 48: 271-276. DOI: $10.1002 /($ SICI)10970126(199904)48:4<271::AID-PI119>3.0.CO;2-J

Griffith, L.G., 2000. Polymeric biomaterials.Acta Mater., 48: 263-277. DOI: 10.1016/S13596454(99)00299-2

Jacob, M.M.E. and A.K. Arof, 2000. FTIR studies of DMF plasticized polyvinyledene fluoride based polymer electrolytes. Electrochimica Acta, 45: 1701-1706. DOI: 10.1016/S0013-4686(99)00316-3

Jiang, F., H. Horber, J. Howard and D.J. Muller, 2004. Assembly of collagen into microribbons: Effects of ph and electrolytes. J. Struct. Biol., 148: 268-278. DOI: 10.1016/j.jsb.2004.07.001

Kull, K.R., M.L. Steen and E.R. Fisher, 2005. Surface modification with nitrogen-containing plasmas to produce hydrophilic, low-fouling membranes. J. Membrane Sci., 246: 203-215. DOI: 10.1016/j.memsci.2004.08.019

Lanceros-Mendez, S., J.F. Mano, A.M. Costa and V.H. Schmidt, 2001. FTIR and DSC studies of mechanically deformed $\beta$-PVDF films. J. Macromolecular Sci. Part B: Phys., 40: 517-527. DOI: $10.1081 / \mathrm{MB}-100106174$
Lowe, C.R. 2000. Nanobiotechnology: the fabrication and applications of chemical and biological nanostructures. Curr. Opin. Struct. Biol., 10: 428434. DOI: $10.1016 / \mathrm{S} 0959-440 \mathrm{X}(00) 00110-\mathrm{X}$

Maeda, H., 1999. An atomic force microscopy study of ordered molecular assemblies and concentric ring patterns from evaporating droplets of collagen solutions. Langmuir, 15: 8505-8513. DOI: 10.1021/la9817381

Majid, S.R. and A.K. Arof, 2007. Electrical behavior of proton-conducting chitosan-phosphoric acid-based electrolytes. Phys. B: Condensed Matter, 390: 209215. DOI: 10.1016/j.physb.2006.08.038

Mano, J.F., V. Sencadas, A.M. Costa and S. LancerosMendez, 2004. Dynamic mechanical analysis and creep behaviour of $\beta$-PVDF films. Mater. Sci. Eng. A, 370: 336-340. DOI: 10.1016/j.msea.2002.12.002

Meng, J.Q., C.L. Chen, L.P. Huang, Q.Y. Du and Y.F. Zhang, 2011. Surface modification of PVDF membrane via AGET ATRP directly from the membrane surface. Applied Surface Sci., 257: 6282-6290. DOI: 10.1016/j.apsusc.2011.02.062

Nasir, N.F.M., M.G. Raha, K.N. Kadri, M. Rampado and C.A. Azlan, 2006. The study of morphological structure, phase structure and molecular structure of collagen-PEO $600 \mathrm{~K}$ blends for tissue engineering application. Am. J. Biochem. Biotechnol., $\quad 2$ : 175-179. DOI: 10.3844/ajbbsp.2006.175.179

Salimi, A. and A.A. Yousefi, 2003. Analysis method: FTIR studies of $\beta$-phase crystal formation in stretched PVDF films. Polymer Test., 22: 699-704. DOI: 10.1016/S0142-9418(03)00003-5

Sun, L.L., B. Li, Z.G. Zhang and W.H. Zhong, 2010. Achieving very high fraction of $\beta$-crystal PVDF and PVDF/CNF composites and their effect on AC conductivity and microstructure through a stretching process. Eur. Polymer J., 46: 2112-2119. DOI: 10.1016/j.eurpolymj.2010.09.003 